Article

\title{
Evaluation of River Network Generalization Methods for Preserving the Drainage Pattern
}

\author{
Ling Zhang ${ }^{1,2,3, *}$ and Eric Guilbert ${ }^{4}$ \\ 1 Key Lab of Virtual Geographic Environment, Nanjing Normal University, Ministry of Education, \\ Nanjing 210023, China \\ 2 State Key Laboratory Cultivation Base of Geographical Environment Evolution, Nanjing 210023, China \\ 3 Jiangsu Center for Collaborative Innovation in Geographical Information Resource Development and \\ Application, Nanjing 210023, China \\ 4 Dept. of Geomatic Sciences, Laval University, Quebec, QC G1V 0A6, Canada; eric.guilbert@scg.ulaval.ca \\ * Correspondence: lingzhang.sky@gmail.com; Tel.: +86-138-1589-3216
}

Academic Editors: Strobl Josef and Wolfgang Kainz

Received: 24 August 2016; Accepted: 23 November 2016; Published: 6 December 2016

\begin{abstract}
The drainage pattern of a river network is the arrangement in which a stream erodes the channels of its network of tributaries. It can reflect the geographical characteristics of a river network to a certain extent because it depends on the topography and geology of the land and as such should be considered during the river network generalization process. There are many methods for river network generalization in tributary selection but most do not explicitly consider the network pattern. Validation of the generalized result is performed visually by an expert and may not be done systematically. An automatic validation technique may help to better understand the results obtained with each method and check whether the pattern has been preserved. This paper proposes an approach to evaluate the quality of a generalized river network by assessing how well its original drainage pattern is preserved. The membership to a drainage pattern is evaluated by a set of geometric indicators, making use of a fuzzy logic approach which allows for a compromise between different criteria depending on the membership values. Three tributary selection methods are tested in this work: selection by stroke and length, catchment area, and a manually generalized network. Assessing the quality of a generalization is done by comparing pattern memberships before and after generalization. This research provides a quantitative indicator to assess the generalized river network in preserving geographical information.
\end{abstract}

Keywords: drainage pattern; river network; generalization; evaluation

\section{Introduction}

Automated map generalization is always an important issue and a major challenge in cartography and Geographical Information System (GIS) research. Regarded as the skeleton of the terrain, the drainage system is already considered to preserve terrain features in generalization [1]. However, in river network generalization, the focus is on individual stream selection and more global information describing the drainage system (such as the drainage pattern) is not considered. There are several reasons: (1) rivers are an important part of the land, and need to be represented on maps of any kind; and (2) rivers are fundamental concepts used for various analyses in geo-science. For instance, geologists can extract the original terrain structure and perform terrain analysis from the drainage system [1-3].

Recently, many researchers have started to pay attention to geographical features of river networks during the generalization process [4-6], which follows the idea that "generalization is not a mere reduction of information-the challenge is one of preserving the geographic meaning" [7]. The nature of the pattern of 
water bodies is influenced by some geographical factors, such as topography, soil type, and bedrock type [8]. Considering drainage pattern in river network generalization helps to retain the geographical meaning of the networks. There are several types of drainage patterns. They are commonly classified as dendritic, parallel, trellis, rectangular, radial, centripetal and reticulate patterns [9]. Dendritic patterns, also named tree-like patterns, can usually be found where there is no strong geological control [10]. Parallel, trellis and rectangular drainage patterns develop in areas with strong regional slopes and have their own specific characteristics. Streams radiating from a high central area form a pattern of radial drainage, while streams forming a centripetal one gather in low-lying land. Reticulate drainage patterns are usually found on floodplains and deltas where rivers often interlace with each other [11]. The first four drainage patterns are illustrated in Figure 1.

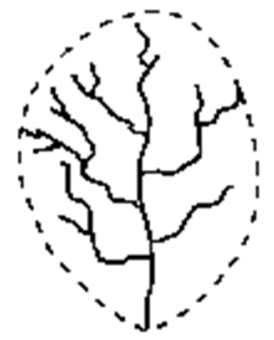

(a)

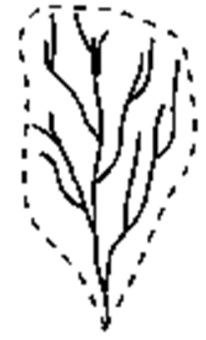

(b)

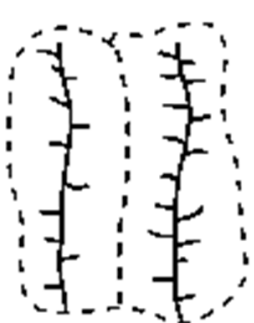

(c)

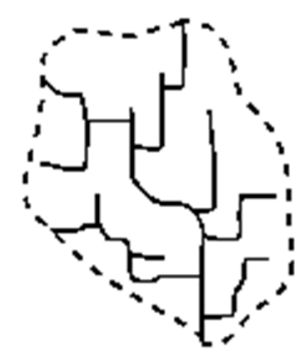

(d)

Figure 1. Drainage patterns. (a) is an illustration of dendritic pattern; (b) is a parallel pattern; (c) is a trellis pattern and (d) is rectangular pattern.

As a set of line features, river networks are generalized from a large scale to a small scale in two main steps: selective omission and selected tributaries simplification [12]. There are many methods for selective omission and simplification of tributaries for rivers selected as individual line features but, while most research focuses on river networks during the generalization, generalized results are still inspected by expert cartographers visually. Drainage patterns can be considered in river network generalization as patterns are important in generalization and should be explicitly measured and evaluated [13]. As the geological environment of a drainage basin does not change with the map scales, the drainage pattern in the basin should be the same before and after generalization. Limited concern has been given to evaluate whether the geographical meaning, including the drainage pattern, is preserved during the process.

Extending recent works by Zhang and Guilbert [14], who presented an automatic classification technique, this paper proposes a method that estimates whether a drainage pattern is preserved or not during its generalization. The method applies to river networks defined by a hierarchical structure in vector mode and can identify patterns shown in Figure 1. In their work, the authors of [14] identified the drainage pattern by a fuzzy logic approach which allows for a compromise between different criteria depending on the membership values. Therefore, the method can be applied to evaluate the performances of stream selection techniques in preserving patterns, and is used to measure the quality of a generalized network by assessing if its geographic meaning is emphasized, preserved or even lost. This paper provides a quantitative indicator to evaluate the river network generalization in preserving geographical information.

The paper is organized as follows: Section 2 reviews related work on tributary selection and generalization evaluation. Section 3 describes the new evaluation method, including pattern classification and the measurement of the result. In Section 4, the method is applied to a case study, and results from two automatic generalization methods are presented. Performances of the methods are discussed for different patterns. Finally, the last section provides concluding remarks about the method and directions for further works on river network classification and generalization. 


\section{Related work}

\subsection{Tributary Selection Methods}

One objective of generalization is to guarantee that when moving to a smaller scale, the number of objects is reduced but meaningful information is preserved or even emphasized. Therefore, questions need to be answered as to how many river tributaries have to be removed (or retained) and which of these should be removed.

In map generalization, a classical principle of selection, the so-called "Radical Law", was established by Topfer in 1961 [15]. The method is given as $n_{f}=n_{a} \sqrt{M_{a} / M_{f}}$, where $n_{f}$ is the number of objects shown at the smaller scale $M_{f}$, and $n_{a}$ is the number of objects shown at the larger scale $M_{a}$. This method is a basic principle, a modified equation is also provided as $n_{f}=n_{a} C_{b} C_{z} \sqrt{M_{a} / M_{f}}$, where $C_{b}$ is the "Constant of Symbolic Exaggeration" and $C_{z}$ is the "Constant of Symbolic Form" [15]. For a specific situation, new factors should be taken into consideration in hydrographic data generalization. In addition, Wilmer and Brewer [16] evaluate the United States Geological Survey (USGS) National Hydrography Dataset and National Atlas hydrography to determine the existing length of features for comparison to expected results based on the Radical Law equation. The rate of feature selection is not the same along the continuum of scale. So, a factor called "Constant of Flowlines" $\left(C_{f}\right)$ is added to the basic equation, and the modified equation is $n_{f}=n_{a} C_{f} \sqrt{M_{a} / M_{f}}$.

From the literature review of previous work, the current methods on river network generalization have been well developed, and much work has been done on river network selective omission and selected tributaries simplification. The question of which tributaries should be removed is considered through different stream selection methods. It has been assessed by Mazur and Castner [17] that ordering schemes [18] are the most significant parameters to consider in stream selection. Therefore, the most commonly used methods are based on the Horton-Strahler order-the higher the order (and therefore closer to the main stream), the more important the stream is—and the stream length - the longer the stream, the more important it is [19]. Thomson and Brooks [20] built strokes to organize river networks based on the Gestalt recognition principles and applied it to generalization by judging the main channel and omitting less important channels. A mainstream is detected based on the strokes using their Horton order and their length. However, determining the main stream using the longest path on clipped river network causes large errors. Touya [21] presents a method for river network selection that relies on the organization of river strokes in hierarchy. His work adds the management of river islands and irrigation zones, and allows the building of strokes in a clipped area where some sources are not natural. However, it only focuses on the geometric aspect of river networks, and it does not select tributaries according to the physiography of the terrain.

Since the distribution of river networks is associated with the terrain surface, Wolf [22] builds a weighted network data structure integrating the drainage, ridges, and peak and pit points. This data structure can determine the significance of a river. The river tree structures have various patterns leading to different generalization strategies. Wu [23] investigates the characteristics of the river tree and develops a method based on buffer spatial analysis to establish the river tree structure. Ai et al. [4] present a method where streams are selected according not to their length but to their watershed area. In order to consider different factors, such as river length, river tributaries spacing, catchment area, and river network density, a multi-objective optimization process in river tributary selection was developed. Zhai et al. [24] built a structured river data model regarding the river system's spatial knowledge, and selected river tributaries automatically based on a genetic multi-objective optimization algorithm. In their model, the indicators, such as length, interval and importance of a river, were taken into account while selecting the rivers.

These methods are still based on topological and geometrical parameters and do not consider the type of terrain or network being processed. Such types of information were taken into account to define specific techniques related to the physiography of the terrain $[5,25]$. The parameters of density 
and the upstream drainage area are also used to prune the river network [6,26]. For man-made ditches, Savino et al. [27] present a typification method for generalization of groups of ditches, which are represented as a regular pattern of straight lines.

\subsection{Generalized River Network Quality Assessment}

Research on assessing generalization results has drawn little attention so far $[28,29]$. Traditionally, generalization is evaluated visually by cartographic experts and their quality graded through questionnaires [30]. This method is based on experts' knowledge and experience, which is rather subjective [31,32] and methods to quantify generalization results should be developed [31]. Bard [33] proposed a general method to evaluate cartographic generalization. The quality of generalized results is evaluated by an assessment model which compares the characterizations of the data before and after generalization. However, the method has been implemented and tested in small urban areas only. For the quality assessment of river network generalization, especially in the operation of selective omission, related works are few. Results are usually assessed locally by checking the legibility of the data (whether objects are cluttered on the map or lines are not too complex) and globally by assessing if main rivers have been preserved. Methods must also maintain the topologic structure of the network, i.e., no gap must be created. It is important that a Coefficient of Line Correspondence (CLC) be calculated to compare generalized data with original data [5,6,34]. CLC is given based on length only, which cannot assess the generalized river network comprehensively. Regarding river tributaries simplification, only some related studies focus on line features as single geometric primitives [31,35].

These methods are, like the selection methods, mostly based on geometrical and statistical criteria and consider river streams as individual objects. Information conveyed by the network related to the drainage pattern and preservation of the terrain physiology is not taken into account by selection methods and is not assessed in the evaluation of the final result otherwise than visually. Some recent works have pointed out the importance of modeling and maintaining geospatial patterns and structures in cartographic generalization $[13,36]$. Such considerations can indeed be made for stream selection where a river network can be seen as a geographic object with its own structure, represented by its drainage pattern, which shall be maintained when removing tributaries. Therefore, a specific measure can be defined to evaluate whether such pattern has been preserved and if different selection approaches have an impact on the representation of drainage patterns on the map. The next section will provide an evaluation method to check how much the generalized river network preserves its drainage pattern. It includes the classification of sub-networks within a drainage system into different patterns and the comparison of the different patterns obtained.

\section{Assessment of Drainage Pattern Preservation in River Generalization}

\subsection{Drainage Pattern Classification}

Drainage patterns are constrained by the underlying terrain morphology and describe the organization of tributaries along a stream. This organization can be defined by different variables translating qualitative descriptions into quantitative indicators describing the geometric properties of the network. They relate to the junction angle between streams, the shape of tributaries and the networks. Zhang and Guilbert [14] use four different indicators to characterize the four drainage patterns presented in Figure 1: the average junction angle $(\alpha)$, the bent tributaries percentage $(\beta)$, the average length ratio $(\gamma)$ and the catchment elongation $(\delta)$ (Table 1$)$. 
Table 1. List of geometric indicators.

\begin{tabular}{ll}
\hline \multicolumn{1}{c}{ Indicator } & \multicolumn{1}{c}{ Description } \\
Average junction angle $(\alpha)$ & $\begin{array}{l}\text { The angle is composed by upper tributaries. } \alpha \text { is } \\
\text { given by the average value of angles measured at } \\
\text { all junctions in a river network. }\end{array}$ \\
Bent tributaries percentage $(\beta)$ & $\begin{array}{l}\text { Sinuosity is the ratio of the channel length to the } \\
\text { valley length [37]. A channel is considered to be } \\
\text { bent if sinuosity } \geq 1.5 \text { [9]. } \beta \text { is calculated as the } \\
\text { number of bent tributaries divided by the total } \\
\text { number of tributaries. }\end{array}$ \\
Average length ratio $(\gamma)$ & $\begin{array}{l}\text { Length ratio is the ratio of the tributary length to } \\
\text { the main stream length. } \gamma \text { is the average value of } \\
\text { all length ratios in a network. }\end{array}$ \\
Catchment elongation $(\delta)$ & \begin{tabular}{l} 
A ratio of the depth to the breadth of a catchment. \\
\hline
\end{tabular}
\end{tabular}

Indicator values can be computed for each network, however a pattern is based on a combination of different indicator values and membership to a given pattern depends on the relative importance of each value. The membership value is defined using fuzzy logic [38] in order to compare membership to each pattern. Each indicator value is defined on a fuzzy set with appropriate membership functions (MF) varying between 0 and 1 . Membership to each pattern is then defined by a fuzzy rule combining the membership value of each indicator.

In fuzzy logic, the usage of an indicator is described by a predicate. There are eight predicates in the classification process:

- $\alpha$ IS acute/very acute/right,

- $\quad \beta$ IS bent,

- $\gamma$ IS long/short,

- $\delta$ IS broad/elongated.

The value of a predicate is given by an MF which is most commonly a polynomial function varying between 0 and 1 . For example, the predicate " $\alpha$ is acute" will return a value equal or close to 1 if the angle $\alpha$ is small, and a value equal or close to 0 when $\alpha$ is large. Each pattern is characterized by a combination of predicates defined by IF-THEN rules:

- $\quad$ IF ( $\alpha$ IS acute) AND ( $\delta$ IS broad) THEN pattern IS dendritic.

- $\quad$ IF ( $\alpha$ IS very acute) AND NOT ( $\beta$ IS bent) AND ( $\gamma$ IS long) AND ( $\delta$ IS elongated) THEN pattern IS parallel.

- IF ( $\alpha$ IS right) AND NOT ( $\beta$ IS bent) AND ( $\gamma$ IS short) AND ( $\delta$ IS elongated) THEN pattern IS trellis.

- $\quad$ IF ( $\alpha$ IS right) AND ( $\beta$ IS bent) THEN pattern IS rectangular.

Figure 2 shows examples of classification for different types of drainage. Although classification depends on membership function definitions, experimentations conducted by Zhang and Guilbert [14] showed that the method can classify drainages correctly with a few that remain unclassified. From their research, the classification is also robust as an alteration of MF parameters has a limited impact on the result. Unclassified drainages correspond to cases where membership is too low to take a decision, either because the drainage does not follow any of the definition above or because the network has too small a number of tributaries (two or three) to conclude. 


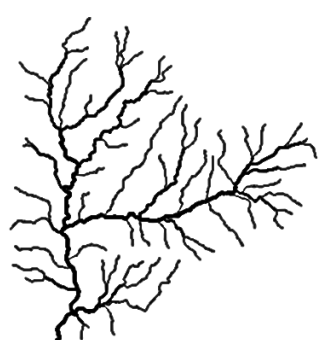

(a)

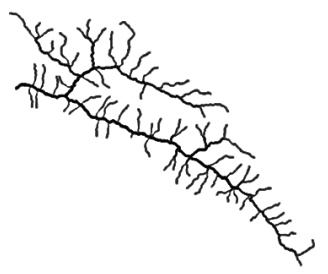

(b)

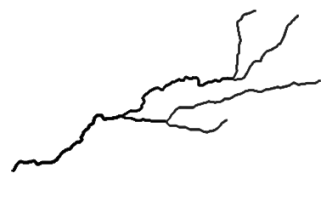

(c)

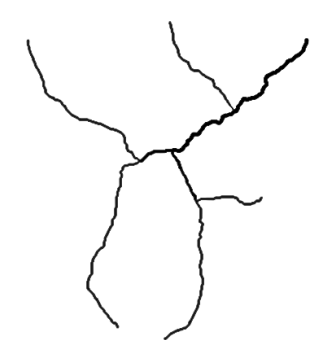

(d)

Figure 2. Examples of drainage classification. (a) is classified as a dendritic network; (b) is recognized as a trellis network; (c) is a typical parallel network; (d) is an unclassified network.

\subsection{Evaluation of Generalized Networks}

Following this method, the drainage pattern of a river network can be recognized automatically. The method can be applied to assess if the pattern of a generalized river network was modified or not after generalization. Considering the indicators defined in the previous section, a network can be assigned a membership value for each pattern and the network's pattern is determined by the highest membership value. This value provides a score of how characteristic the pattern is. Therefore, the score can be used to evaluate the drainage pattern after generalization. If the network belongs to the same pattern, then the drainage pattern has been preserved. If the membership value for this pattern has increased, it can be considered that its drainage characteristic has been emphasized.

A drainage system can be partitioned into a hierarchy of systems and each of them can be characterized by its own pattern. In the context of our work, the river network of a system is defined by its main river (connecting to the outlet) and all its tributaries. A hierarchy of river networks, each of them forming a drainage system, can be designed. Each network can be classified so that when assessing a generalized network, pattern preservation can be evaluated at different levels.

Depending on the amount of generalization, a network can be generalized by being deleted (all its streams are deleted or only one stream remains), brought to a lower order or maintained at the same order. Each stream of the network is identified by an ID number. Therefore, generalized drainages can be linked to their original drainages by taking the two networks which have the same main stream and compared.

Assessing the performances of a generalization method is done as follows:

For a network defined at large scale, compute the Horton order of each stream and classify all drainage systems at all levels.

1. Generalize the network by applying a stream selection method.

2. Evaluate the pattern of all drainages in the new network.

3. For each drainage in the simplified network, find its equivalent drainage in the original network according to the stream ID, then compare them to check if the pattern has been preserved.

\section{Experimentation Design}

The method of the previous section is applied to the comparison of two generalization techniques, a first method based on strokes and stream length [20] and a second method based on the drainage basin area [4]. The former is the most commonly used method for tributary selection [12], and the second method is based on a different indicator. They are two typical methods for river network generalization. Techniques are compared by applying both methods on the same network where the number of tributaries to be selected is fixed.

Experimentation is conducted first by comparing results obtained for both methods with a manual generalization of the network. Second, generalizations at smaller scales are performed and results are evaluated by looking at changes in drainage classification. 


\subsection{Tributary Selection by Stroke and Length}

Thomson and Brooks [20] proposed the "stroke" concept and applied it to generalization and analysis for geographic networks such as road and river networks. In their work, the Horton stream ordering after upstream routine is used to build the strokes of a river network. The Horton-Strahler order scheme is first performed, and then an upstream routine is applied to determine the main stream [12]. Here, in a river network, the main stream is referred to as a "stroke" because it is a path of good continuation: it moves through the network with no abrupt change in direction [39]. Figure 3 shows the strokes of a river network.

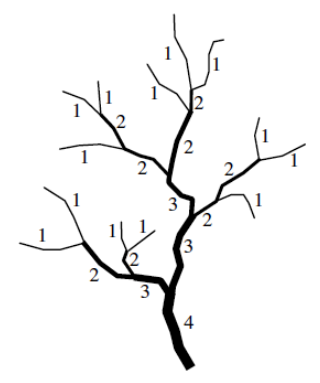

(a)

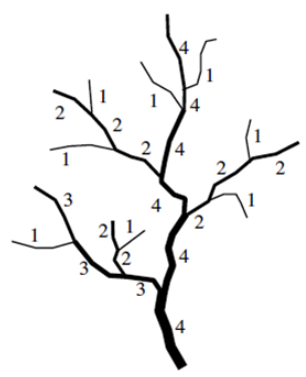

(b)

Figure 3. "Strokes" of a river network (from Li's work [12]). (a) is a river network performed by the Horton-Strahler order scheme. (b) is the network after upstream routine, main streams are regarded as strokes.

Tributary selection based on order can be done in four possible ways [17]. The easy way is to eliminate all low order tributaries and preserve high order tributaries in the first place. The drawback is that all tributaries in an order will be removed in a step. Sometimes, in a specific scale, some tributaries should be preserved in an order. Therefore, the length is a factor taken into consideration.

Similarly, taking a stroke as an entity, there are two steps in the generalization process: (1) remove the low order stroke first; (2) remove the shorter strokes if they are in the same order.

\subsection{Tributary Selection by Watershed Partitioning}

Ai et al. [4] proposed a method constructing a hierarchy of different level watersheds. It focuses on the channel importance during the river network generalization replacing several geometric parameters of a river feature by its watershed area. The watershed area is not obtained from the Digital Elevation Model (DEM) but constructed on spatial competition by triangulations of the network. The Triangulated Irregular Network (TIN) is constructed by constraining edges with river segments. The selection method eliminates tributaries according to the catchment area. The tributary with smaller catchment area is removed first. An example of the hierarchical watershed partitioning is shown in Figure 4.

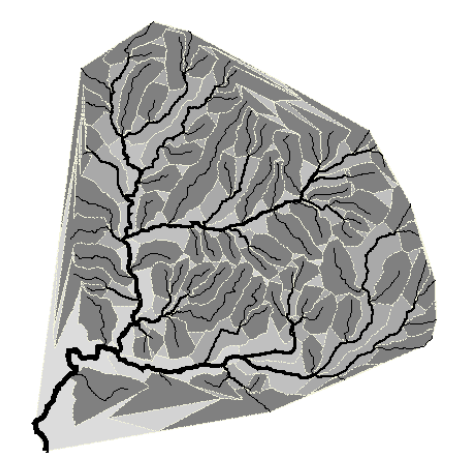

Figure 4. An example of hierarchical partitioning of river catchments. 
Consequently, the catchment area is the area of the watershed polygon. For a simple polygon with $n$ vertices $\left(x_{i}, y_{i}\right)(1 \leq I \leq n)$, the first and last vertices are the same, i.e., $x_{n}=x_{1}$, and $y_{n}=y_{1}$. The area is given by the Surveyor's formula [40]:

$$
\mathrm{A}=\frac{1}{2}\left|\sum_{i=1}^{n-1}\left(x_{i} y_{i+1}-x_{i+1} y_{i}\right)\right|,
$$

where $A$ is the area of the polygon. If the vertices are stored sequentially in the counterclockwise direction, the absolute value sign in the formula can be omitted.

In the experiment, in order to assess whether a river network maintains the same drainage pattern after generalization, three generalization methods are tested (Table 2). The first two are automatic, and the last one is the manually generalized data.

Table 2. Testing on three generalization methods.

\begin{tabular}{ccc}
\hline No. & Approaches & Methods \\
\hline I & Hierarchy & Wtroke + Length \\
II & Watershed partitioning (Catchment) \\
III & Manual & \\
\hline
\end{tabular}

\subsection{Testing Data}

Datasets of the Russian river located in California, USA are tested in the experiment. Two different scales are used: 1:24,000-scale $(1: 24 \mathrm{~K})$ and 1:100,000-scale $(1: 100 \mathrm{~K})$. The 1:24K data is stored in a Shapefile from the Russian River Interactive Information System (RRIIS). The 1:100K data is from the National Hydrography Dataset (NHD) of the USA. The 1:24K hydrographic data are compiled first, and much of these data have been translated into the first version of the NHD. The 1:100K hydrographic data are manually scribed from the blue-lines of the $1: 24 \mathrm{k}$ photo-reduced mosaics. Thus, the $1: 100 \mathrm{k}$ data is a generalized version of the 1:24k one, which respects compilation standards controlling manual procedures [41], and it can be regarded as a partially manual work. The Horton-Strahler order scheme was then computed. The test data are illustrated in Figure 5.

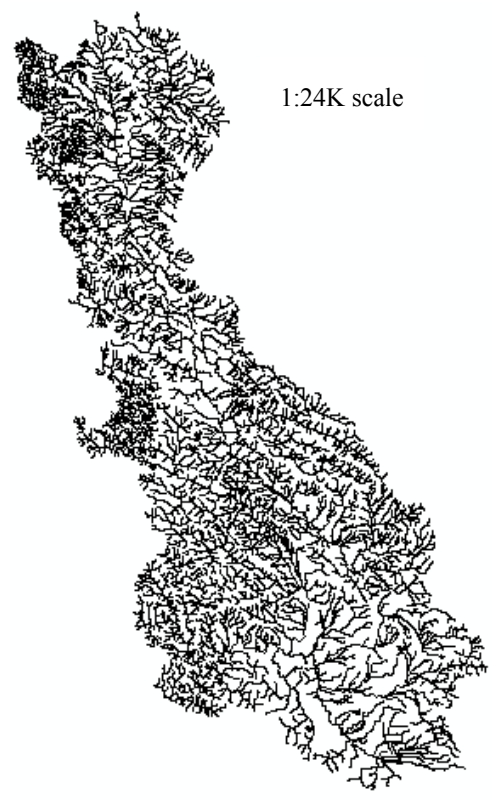

(a)

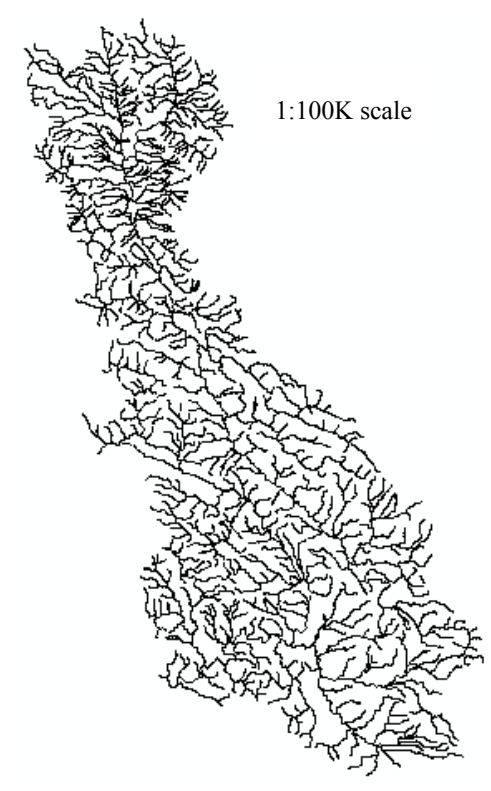

(b)

Figure 5. Experiment datasets. (a) is the Russian river dataset at 1:24K scale from RRIIS; (b) is the same area dataset at 1:100K scale from the National Hydrography Dataset (NHD). 
To apply the Radical Law in NHD, the constant $C_{f}$ ("Constant of Flowlines") in the equation can take three possible values according to the scale [16]: 1, 1.7 and 0.6 . The value 1 corresponds to large scale $(1: 24 \mathrm{~K})$ to medium scale $(1: 100 \mathrm{~K}), 1.7$ is for local scale $(1: 5 \mathrm{~K})$ to other scale, and 0.6 for changes between small scales (1:2M). Hence a constant of 1 is used in the experiment.

\subsection{MF Parameter Settings}

Classifying drainages according to their patterns relies on the definition of membership functions, including several threshold parameters. This parameter setting is adopted from the previous work [14]. The MF of each predicate are presented in Table 3, and the graphical illustration is shown in Figure 6.

Table 3. Membership function (MF) parameter settings for testing. $z(\alpha ; a, b)$ is asymmetrical polynomial curves open to the left where $\alpha$ is the junction angle and $a$ and $b$ locate the extremes of the sloped portion of the curve; $s(\alpha ; a, b)$ is opposite curve to $\mathrm{Z}$ curve; and $g(\alpha ; \sigma, m)$ is a Gaussian distribution curve where $m$ is the center and $\sigma$ controls the width of the curve.

\begin{tabular}{cc}
\hline Predicate & MF \\
\hline$\alpha$ IS acute & $\mathrm{z}\left(\alpha ; 45^{\circ}, 90^{\circ}\right)$ \\
$\alpha$ IS very acute & $\mathrm{z}\left(\alpha ; 30^{\circ}, 60^{\circ}\right)$ \\
$\gamma$ IS short & $\mathrm{z}(\gamma ; 0,1)$ \\
$\delta$ IS broad & $\mathrm{z}(\delta ; 1,3)$ \\
$\alpha$ IS right & $\mathrm{g}\left(\alpha ; 10^{\circ}, 90^{\circ}\right)$ \\
$\beta$ IS bent & $s(\beta ; 0,1)$ \\
$\gamma$ IS long & $s(\gamma ; 0,1)$ \\
$\delta$ IS elongated & $s(\delta ; 1,3)$ \\
\hline
\end{tabular}

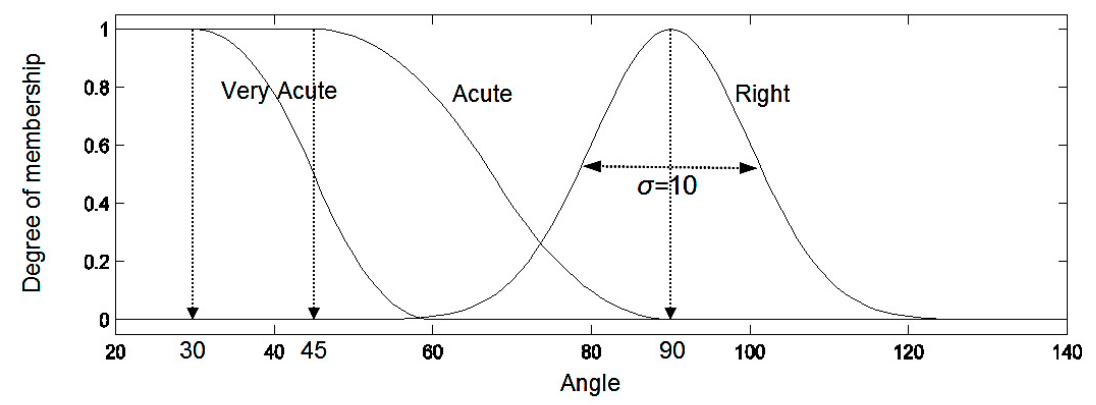

(a)

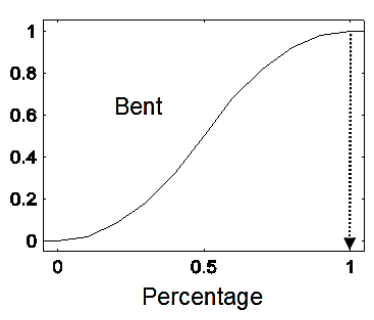

(b)

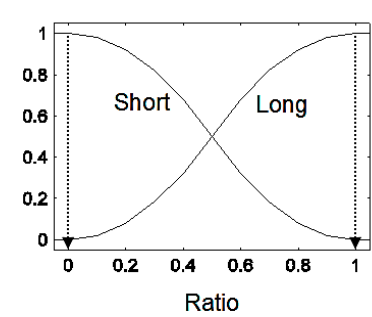

(c)

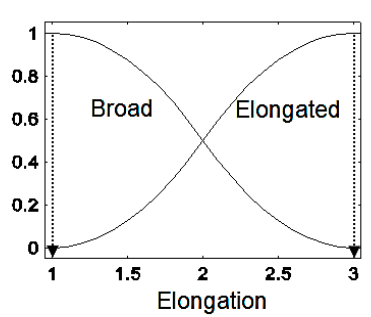

(d)

Figure 6. MFs. (a) shows MFs for very acute, acute and right angle, input is the junction angle $\alpha$; (b) shows the MF for bent tributaries, the input is bent tributaries percentage $\beta$; (c) shows the MF for a short tributary, input is average length ratio $\gamma ;(\mathbf{d})$ shows the MF for elongated catchment, input is catchment elongation $\delta$.

Tributary selection is performed for different scales and for one case, results are compared with results obtained by manual selection. 


\section{Experiment results}

\subsection{Case Studies in Russian River}

\subsubsection{Case 1: A Dendritic River Network}

Figure 7a shows the tested river network for this case. It is a typical dendritic network with a membership value of 0.933 . The river network with Horton-Strahler order after upstream routine is illustrated in Figure $7 \mathrm{~b}$, which is used to select tributaries by stroke and length.

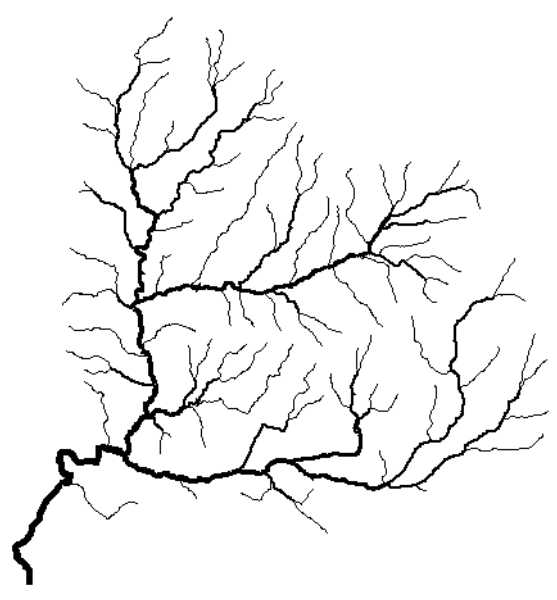

(a)

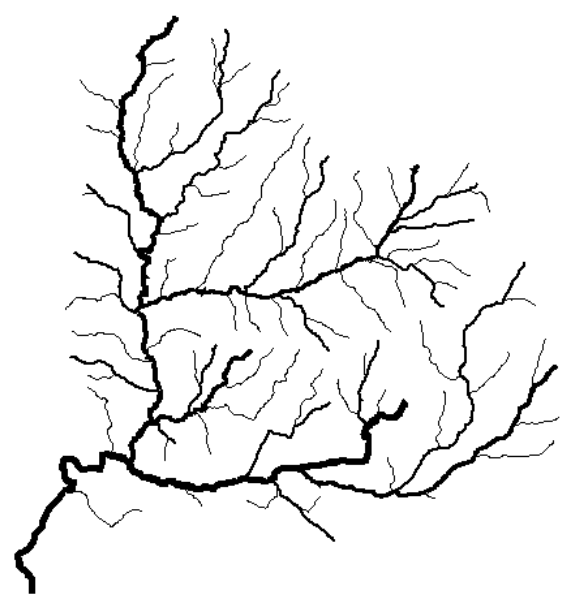

(b)

Figure 7. Tested river network for dendritic case. (a) is the dendritic network schemed by Horton-Strahler order; (b) is the network with Horton-Strahler order after upstream routine. The bolder the river tributary, the greater the Horton-Strahler order.

\section{(1) Comparing results with manual case}

Generalized river networks by the three methods are illustrated in Figure 8. The manual generalized river network at 100K scale from the NHD is shown in Figure 8c. Too many tributaries have been removed and it does not follow the selection principle of Radical Law. Tributaries are eliminated by stroke and catchment according to the amount of the manual one, so that they can be compared at the same level. River networks generalized by stroke and catchment are shown in Figure $8 \mathrm{a}, \mathrm{b}$ respectively.

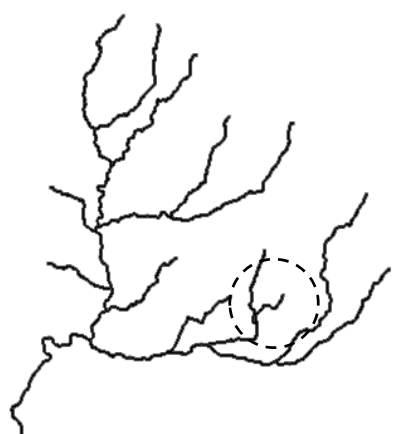

(a) Stroke + Length

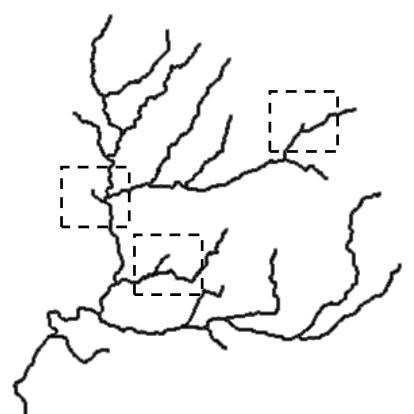

(b) Catchment

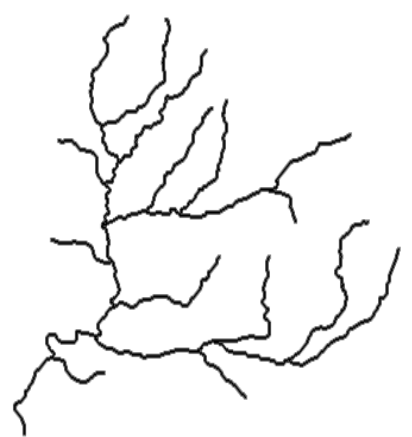

(c) Manual

Figure 8. Generalized networks by three methods for dendritic case. (a) Stroke + Length; (b) Catchment; (c) Manual. 
In Figure 8, all generalized networks are good for visual assessment. However, the manual network is better than others in some respects. For example, the tributary in the dashed circle in network (a) is short with a twist that should be eliminated. It is preserved in network (a) because its order is greater than other longer tributaries. There are some short tributaries maintained in network (b) generalized by catchment which are shown in dashed boxes. Network (a) is better than (b); and (c) is the best.

Table 4 shows the assessment result of generalized river networks by the three methods. From the table, the membership value of manual network is 0.869 , which is the greatest among all generalized networks. Membership values of network (a) and (b) are 0.801 and 0.730 respectively. Network (a) is better than (b) from the membership, and that is also confirmed by visual assessment.

Table 4. Assessment result of generalized networks in Figure 8 where " $\mathrm{D}$ ", " $\mathrm{P}$ ", " $\mathrm{T}$ " and " $\mathrm{R}$ " stand for dendritic, parallel, trellis and rectangular patterns respectively.

\begin{tabular}{cccccccccc}
\hline Method & \multicolumn{4}{c}{ Indicator } & \multicolumn{4}{c}{ Membership Value } \\
\hline & & $\boldsymbol{\alpha}$ & $\boldsymbol{\beta}$ & $\boldsymbol{\gamma}$ & $\boldsymbol{\delta}$ & $\mathbf{D}$ & $\mathbf{P}$ & $\mathbf{T}$ & $\mathbf{R}$ \\
\cline { 3 - 11 } Stroke + Length & (a) & $59.19^{\circ}$ & $4.00 \%$ & 1.10 & 1.20 & 0.801 & 0.002 & 0 & 0.003 \\
Catchment & (b) & $61.52^{\circ}$ & $8.57 \%$ & 0.58 & 1.16 & 0.730 & 0 & 0.013 & 0.015 \\
Manual & (c) & $56.52^{\circ}$ & $10.34 \%$ & 0.64 & 0.99 & $\mathbf{0 . 8 6 9}$ & 0 & 0 & 0.004 \\
\hline
\end{tabular}

(2) Comparing results at different scales

Table 5 shows generalized networks by stroke and catchment at different scales. In this case study, 1:100K, 1:250K, 1:500K, 1:1M and 1:5M scales are tested. Due to the different methods of structure construction, the numbers of strokes and catchments are different. So, the Radical Law is used to decide how many features are eliminated for each method. In the table, the river network (a) is the original data at a $24 \mathrm{~K}$ scale used for comparison. All generalized results are good, but in general, the stroke and length method provides better results by visual checking. At a 1:100K scale, network (c) has more short tributaries due to the shortage of the method, and (b) has better details in the dashed box than (c). At the 1:250K, 1:500K and 1:1M scales, networks (d), (f) and (h) look more balanced than (e), (g) and (i) respectively. Here, the balance is used to check whether the number of tributaries are similar for both sides of a stream. The first method eliminates tributaries based on strokes that keep the tributaries straighter and longer than the second method. It can be verified visually from the results of (e), (g) and (i) compared to (d), (f) and (h) respectively. At a 1:5M scale, network (j) has a better shape than $(\mathrm{k})$ as the skeleton of the original network is well maintained in network (j). Obviously, network (j) is better than (k) at this scale.

The assessment result for the generalized river networks by different methods at different scales during the generalization process is listed in Table 6, and it shows the same findings with the visual assessment. At the 1:100K, 1:250K, 1:500K, 1:1M and 1:5M scales, the membership values of the generalized networks by stroke are $0.869,0.884,0.762,0.801$ and 0.561 respectively, and they are greater than the values by catchment at each scale. At the $1: 100 \mathrm{~K}$ scale, the difference of the memberships between the two methods is very small, which also confirms visually that river network (b) and (c) in Table 5 are both acceptable. From the membership value of network (k), the pattern changed from dendritic to rectangular. Therefore, network $(\mathrm{j})$ is better than $(\mathrm{k})$ at the 1:5M scale, which also corresponded to the visual assessment. Overall, the stroke method brings better results than the catchment method in this case study from the membership values. 
Table 5. Generalized river network for dendritic case at different scales.

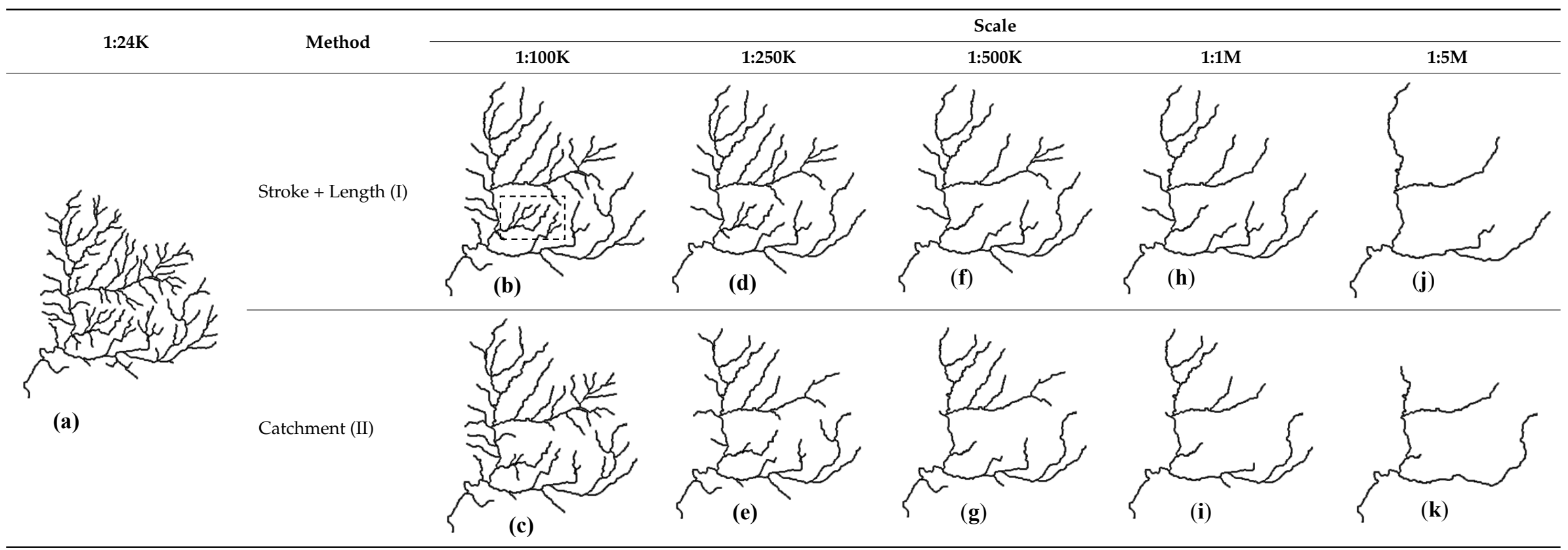


Table 6. Assessment result of dendritic case at different scales.

\begin{tabular}{|c|c|c|c|c|c|c|c|c|c|c|}
\hline \multirow[t]{2}{*}{ Scale } & \multirow[t]{2}{*}{ Method } & & \multicolumn{4}{|c|}{ Indicator } & \multicolumn{4}{|c|}{ Membership Value } \\
\hline & & & $\alpha$ & $\beta$ & $\gamma$ & $\delta$ & D & $\mathbf{P}$ & $\mathbf{T}$ & $\mathbf{R}$ \\
\hline $1: 24 \mathrm{~K}$ & & (a) & $53.24^{\circ}$ & $3.68 \%$ & 0.69 & 1.14 & 0.933 & 0.010 & 0.001 & 0.001 \\
\hline \multirow{2}{*}{ 1:100K } & I & (b) & $55.53^{\circ}$ & $2.53 \%$ & 0.68 & 1.15 & 0.869 & 0.011 & 0.004 & 0.001 \\
\hline & II & (c) & $55.85^{\circ}$ & $3.61 \%$ & 0.86 & 1.21 & 0.861 & 0.022 & 0.004 & 0.001 \\
\hline \multirow{2}{*}{$1: 250 \mathrm{~K}$} & I & (d) & $57.55^{\circ}$ & $4.08 \%$ & 0.90 & 1.20 & 0.844 & 0.013 & 0.005 & 0.003 \\
\hline & II & (e) & $59.26^{\circ}$ & $6.38 \%$ & 0.62 & 1.10 & 0.799 & 0.001 & 0.006 & 0.008 \\
\hline \multirow{2}{*}{$1: 500 \mathrm{~K}$} & I & (f) & $60.51^{\circ}$ & $2.86 \%$ & 0.88 & 1.20 & 0.762 & 0 & 0.013 & 0.002 \\
\hline & II & (g) & $63.76^{\circ}$ & $6.45 \%$ & 0.48 & 1.16 & 0.653 & 0 & 0.014 & 0.008 \\
\hline \multirow{2}{*}{$1: 1 \mathrm{M}$} & I & (h) & $59.19^{\circ}$ & $4.00 \%$ & 1.10 & 1.20 & 0.801 & 0.002 & 0 & 0.003 \\
\hline & II & (i) & $65.16^{\circ}$ & $4.76 \%$ & 0.63 & 1.16 & 0.599 & 0 & 0.014 & 0.005 \\
\hline \multirow{2}{*}{$1: 5 \mathrm{M}$} & I & (j) & $66.08^{\circ}$ & $11.11 \%$ & 1.29 & 1.23 & 0.561 & 0 & 0 & 0.025 \\
\hline & II & $(\mathrm{k})$ & $76.83^{\circ}$ & $42.86 \%$ & 0.63 & 1.18 & 0.171 & 0 & 0.017 & 0.367 \\
\hline
\end{tabular}

\subsubsection{Case 2: A Trellis River Network}

The selected experimental data for this case is a trellis river network shown in Figure 9. In the automatic drainage pattern recognition, the Horton-Strahler order is used for classification. Here, as the river network is already classified as a trellis, the order after upstream routine is used to evaluate generalized results. This is in order to obtain the value of the length ratio indicator based on the same main streams, because the method of stroke and length builds strokes first according to the Horton-Strahler order after upstream routine. The length ratio values will be higher if other methods do not follow the upstream routine as main streams are shorter.

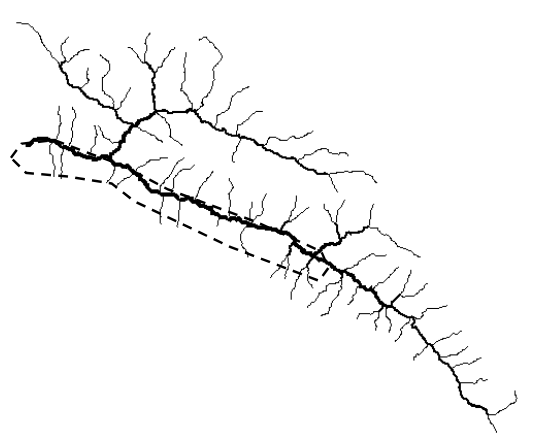

(a)

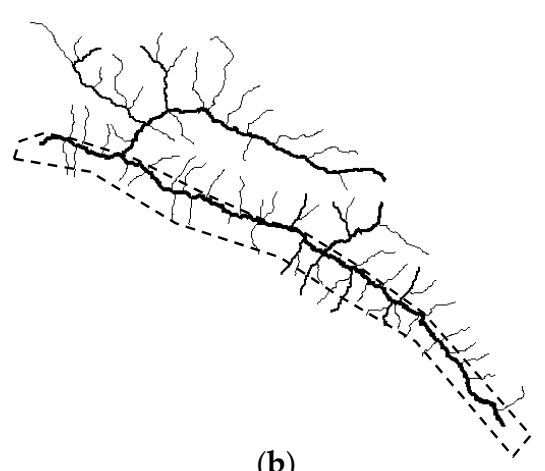

(b)

Figure 9. Tested river network for trellis case. (a) is the trellis network schemed by Horton-Strahler order; (b) is the network with Horton-Strahler order after upstream routine. The bolder the river tributary, the greater the Horton-Strahler order. Dashed polygons show the different main streams obtained owing to different order schemes.

(1) Comparing results with manual case

Figure 10 shows results generalized with the three methods. In the figure, (c) shows the trellis river network from NHD at the 1:100K scale. It also did not meet the requirement of Radical Law as too many tributaries are eliminated at this scale in comparison with the 1:24K scale network. Networks (a) and (b) are generalized to the same number of strokes as the manual one. By checking visually, network (c) is well distributed as it is more balanced than other results, and tributaries are not clustered as tributaries in the dashed circle in network (a). Network (a) is better than (b) because some short tributaries are preserved by the catchment method such as tributaries in the dashed boxes. Network (c) is still the best result among all generalized networks. 


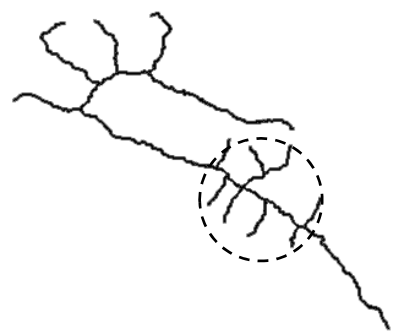

(a) Stroke + Length

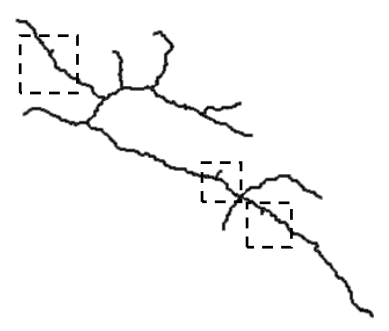

(b) Catchment

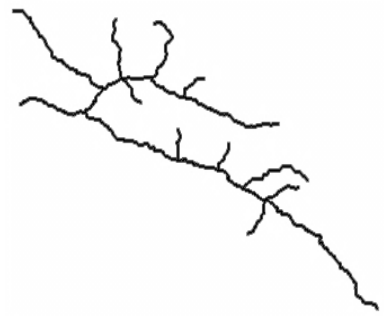

(c) Manual

Figure 10. Generalized networks by three methods for the trellis case. (a) Stroke + Length; (b) Catchment; (c) Manual.

The evaluation result is shown in Table 7 and corresponds to the outcome by visual assessment. The manual network obtains a maximum membership value of all generalized networks. Its membership is 0.842 , which is greater than both 0.684 of network (a) and 0.396 of network (b). From membership values, network (a) generalized by stroke and length is better than (b) by catchment, which is also confirmed by visual checking.

Table 7. Assessment result of generalized networks in Figure 10.

\begin{tabular}{cccccccccc}
\hline Method & \multicolumn{4}{c}{ Indicator } & \multicolumn{4}{c}{ Membership Value } \\
\hline & & $\boldsymbol{\alpha}$ & $\boldsymbol{\beta}$ & $\boldsymbol{\gamma}$ & $\delta$ & $\mathbf{D}$ & $\mathbf{P}$ & $\mathbf{T}$ & $\mathbf{R}$ \\
\cline { 3 - 10 } Stroke + Length & (a) & $98.73^{\circ}$ & $8.33 \%$ & 0.21 & 3.03 & 0 & 0 & 0.684 & 0.014 \\
Catchment & (b) & $103.61^{\circ}$ & $5.00 \%$ & 0.29 & 3.29 & 0 & 0 & 0.396 & 0.005 \\
Manual & (c) & $86.67^{\circ}$ & $4.35 \%$ & 0.28 & 3.65 & 0 & 0 & $\mathbf{0 . 8 4 2}$ & 0.004 \\
\hline
\end{tabular}

(2) Comparing results at different scales

During the generalization process, the trellis river network is handled to generalize from the $1: 24 \mathrm{~K}$ scale to $1: 100 \mathrm{~K}, 1: 250 \mathrm{~K}, 1: 500 \mathrm{~K}, 1: 1 \mathrm{M}$ and $1: 2 \mathrm{M}$ scales in this case. The results of this case study are listed in Table 8, where network (a) is the original trellis river network at 1:24K scale.

In Table 8, visually, at 1:100K scale, network (c) is better than (b) as (c) looks more balanced, but (b) is still an acceptable result. Network (e) preserves more short tributaries and (d) has more long ones due to stroke establishment. From the aspect of length, network (d) is better than (e), because short tributaries should be removed after generalization. The catchment of a tributary receives all catchments of its upper stream, so the catchment area would be large even if its length is short. That is why short tributaries are preserved in networks (e), (g) and (i). Networks (d), (f) and (h) are more satisfying than (e), (g) and (i) respectively. For the generalized results at 1:2M scale, they are both trellis pattern since the tributaries are short and straight and all junction angle are large. However, the tributaries are too few to for discussion of pattern issue. As a result, most of the generalized networks are better by stroke and length than by catchment at each scale except at the 1:100K scale. 
Table 8. Generalized river network for trellis case at different scales.

Method


Table 9 shows the assessment result of the trellis river network during the generalization process. In the table, from the assessment, all generalized networks are preserved as the trellis pattern. At the $1: 100 \mathrm{~K}$ scale the membership of (c) is 0.961 , which is greater than 0.870 of network (b), and is confirmed by visual assessment. The membership values of networks (d) and (e) are almost the same at 0.849 and 0.844 respectively. Network (d) is better than (e), which also corresponds to the results visually. For other scales, the method of stroke and length brings higher membership values than by catchment as they are $0.896>0.568,0.907>0.843$ and $0.679>0.615$ at the1:500K, $1: 1 \mathrm{M}$ and 1:2M scales respectively.

Table 9. Assessment result of trellis case at different scales.

\begin{tabular}{ccccccccccc}
\hline Scale & Method & & \multicolumn{4}{c}{ Indicator } & \multicolumn{4}{c}{ Membership Value } \\
\hline \multirow{2}{*}{$24 \mathrm{~K}$} & & & $\boldsymbol{\alpha}$ & $\boldsymbol{\beta}$ & $\gamma$ & $\delta$ & $\mathbf{D}$ & $\mathbf{P}$ & $\mathbf{T}$ & $\mathbf{R}$ \\
\cline { 4 - 11 } & & (a) & $81.14^{\circ}$ & $1.49 \%$ & 0.20 & 3.17 & 0 & 0 & 0.675 & 0 \\
\hline \multirow{2}{*}{$100 \mathrm{~K}$} & I & (b) & $84.72^{\circ}$ & $1.56 \%$ & 0.20 & 3.35 & 0 & 0 & 0.870 & 0.001 \\
& II & (c) & $88.25^{\circ}$ & $1.67 \%$ & 0.14 & 3.17 & 0 & 0 & $\mathbf{0 . 9 6 1}$ & 0.001 \\
\hline \multirow{2}{*}{$250 \mathrm{~K}$} & I & (d) & $84.28^{\circ}$ & $2.50 \%$ & 0.27 & 3.35 & 0 & 0 & $\mathbf{0 . 8 4 9}$ & 0.001 \\
& II & (e) & $95.83^{\circ}$ & $2.94 \%$ & 0.17 & 3.09 & 0 & 0 & 0.844 & 0.002 \\
\hline \multirow{2}{*}{$500 \mathrm{~K}$} & I & (f) & $96.61^{\circ}$ & $3.57 \%$ & 0.23 & 3.35 & 0 & 0 & $\mathbf{0 . 8 9 6}$ & 0.003 \\
& II & (g) & $100.63^{\circ}$ & $4.55 \%$ & 0.27 & 3.09 & 0 & 0 & 0.568 & 0.004 \\
\hline \multirow{2}{*}{$1 \mathrm{M}$} & I & (h) & $94.13^{\circ}$ & $5.00 \%$ & 0.22 & 3.65 & 0 & 0 & $\mathbf{0 . 9 0 7}$ & 0.005 \\
& II & (i) & $112.24^{\circ}$ & $6.25 \%$ & 0.31 & 3.29 & 0 & 0 & 0.843 & 0.008 \\
\hline \multirow{2}{*}{$2 \mathrm{M}$} & I & (j) & $98.80^{\circ}$ & $8.33 \%$ & 0.25 & 3.65 & 0 & 0 & $\mathbf{0 . 6 7 9}$ & 0.014 \\
& II & (k) & $99.87^{\circ}$ & 0 & 0.29 & 4.13 & 0 & 0 & 0.615 & 0 \\
\hline \multirow{2}{*}{2} & & & & & & & & &
\end{tabular}

\subsection{Evaluation Results in the Russian River}

The evaluation method is applied to the whole Russian river to assess generalized river networks. The data process is as follows: (1) According to the river data from NHD at the 1:100K scale, eliminate tributaries in the Russian river to obtain the manually generalized river network; rebuild the network by combining river segments and reassign the Horton-Strahler order. (2) According to the river segment IDs, obtain the corresponding sub-networks from the Russian river at the 1:24K scale. (3) Generalize the sub-networks by stroke and catchment method to the same number of river segments as the manually generalized networks. (4) Assess each generalized river network by the evaluation method.

Table 10 lists the number of preserved or changed drainage patterns after river network generalization. In the table, the first five rows give the number of preserved patterns, and following rows are the number of changes of each pattern in detail. There are 164 river networks at different orders that are extracted and evaluated. From the table, many of the generalized river networks are preserved drainage patterns by the three methods. There are 90, 108, and 96 generalized river networks that preserve their patterns by manual work, catchment and stroke respectively. Although patterns of many networks changed after generalization, most happen in order 2 . In manual work, 74 generalized networks alter patterns, but $85 \%$ (63/74) of them are in order 2 . Similarly, 79\% (44/56) and $85 \%(58 / 68)$ of changed patterns by catchment and stroke respectively are in order 2 . The possible reason is that indicators from a river network are statistical values, which rely on the number of river segments. If there are few river segments in a river network, the indicators would not be robust enough to reflect the pattern of the river network. Most of the river networks in order 2 have less than five river segments. Therefore, if a river network in order 2 is generalized from the network in order 3 or a higher order, two situations can arise: (1) the pattern does change after generalization; and (2) the evaluation method is not able to compute a score due to insufficient river segments. In addition, from the table, most patterns change from dendritic to parallel, trellis and rectangular. There are about $30 \%$ preserved dendritic networks but the other $70 \%$ are modified to different patterns after generalization. For parallel patterns, most networks preserved their pattern because long streams are kept, so there 
are not so many changes. For trellis patterns, most networks are changed to a parallel or unclassified pattern. It is possible because small perpendicular tributaries are removed in the selective omission so that drainages most likely become parallel (if long main streams are kept) or unclassified. Overall, the method based on catchment is the most robust as it is the one which preserves most patterns. Stroke method is more similar to manual generalization. It turns more dendritic networks to parallel, because it more easily removes small tributaries than other methods; in order terms, catchment method probably preserves small tributaries better if they are isolated as their drainage area is in that case is larger.

Table 10. Number of drainage patterns after generalization. " $\rightarrow$ " means that one pattern changes to another. The order is the Horton-Strahler ordering scheme.

\begin{tabular}{cccccccccc}
\hline & \multicolumn{3}{c}{ Manual } & \multicolumn{3}{c}{ Catchment } & \multicolumn{2}{c}{ Stroke + Length } \\
\cline { 2 - 10 } & Order 2 & Order 3 & Order 4 & Order 2 & Order 3 & Order 4 & Order 2 & Order 3 & Order 4 \\
\hline Dendritic (D) & 15 & 29 & 13 & 14 & 34 & 17 & 13 & 29 & 15 \\
Parallel (P) & 14 & 4 & 0 & 17 & 6 & 0 & 16 & 5 & 0 \\
Trellis (T) & 2 & 6 & 2 & 3 & 7 & 4 & 3 & 6 & 3 \\
Rectangular (R) & 0 & 2 & 1 & 0 & 3 & 0 & 0 & 3 & 1 \\
Unclassified (U) & 2 & 0 & 0 & 2 & 1 & 0 & 2 & 0 & 0 \\
\hline $\mathbf{D} \rightarrow \mathbf{P}$ & 16 & 0 & 0 & 15 & 2 & 0 & 19 & 0 & 0 \\
$\mathbf{D} \rightarrow \mathbf{T}$ & 15 & 2 & 1 & 13 & 2 & 1 & 9 & 5 & 1 \\
$\mathbf{D} \rightarrow \mathbf{R}$ & 9 & 4 & 1 & 5 & 5 & 1 & 9 & 3 & 1 \\
$\mathbf{D} \rightarrow \mathbf{U}$ & 4 & 1 & 0 & 1 & 0 & 0 & 6 & 0 & 0 \\
$\mathbf{P} \rightarrow \mathbf{D}$ & 2 & 1 & 0 & 1 & 0 & 0 & 2 & 0 & 0 \\
$\mathbf{P} \rightarrow \mathbf{T}$ & 3 & 0 & 0 & 0 & 0 & 0 & 1 & 0 & 0 \\
$\mathbf{P} \rightarrow \mathbf{R}$ & 0 & 0 & 0 & 0 & 0 & 0 & 0 & 0 & 0 \\
$\mathbf{P} \rightarrow \mathbf{U}$ & 0 & 0 & 0 & 0 & 0 & 0 & 0 & 0 & 0 \\
$\mathbf{T} \rightarrow \mathbf{D}$ & 0 & 0 & 0 & 0 & 0 & 0 & 0 & 0 & 0 \\
$\mathbf{T} \rightarrow \mathbf{P}$ & 5 & 0 & 0 & 2 & 0 & 0 & 3 & 0 & 0 \\
$\mathbf{T} \rightarrow \mathbf{R}$ & 1 & 0 & 0 & 0 & 0 & 0 & 0 & 0 & 0 \\
$\mathbf{T} \rightarrow \mathbf{U}$ & 1 & 1 & 0 & 2 & 0 & 0 & 3 & 0 & 0 \\
$\mathbf{R} \rightarrow \mathbf{D}$ & 0 & 0 & 0 & 0 & 0 & 0 & 0 & 0 & 0 \\
$\mathbf{R} \rightarrow \mathbf{P}$ & 1 & 0 & 0 & 0 & 0 & 0 & 0 & 0 & 0 \\
$\mathbf{R} \rightarrow \mathbf{T}$ & 3 & 0 & 0 & 3 & 1 & 0 & 3 & 0 & 0 \\
$\mathbf{R} \rightarrow \mathbf{U}$ & 0 & 0 & 0 & 0 & 0 & 0 & 0 & 0 & 0 \\
$\mathbf{U} \rightarrow \mathbf{D}$ & 1 & 0 & 0 & 0 & 0 & 0 & 1 & 0 & 0 \\
$\mathbf{U} \rightarrow \mathbf{P}$ & 0 & 0 & 0 & 1 & 0 & 0 & 0 & 0 & 0 \\
$\mathbf{U} \rightarrow \mathbf{T}$ & 1 & 0 & 0 & 0 & 0 & 0 & 1 & 0 & 0 \\
$\mathbf{U} \rightarrow \mathbf{R}$ & 1 & 0 & 0 & 1 & 0 & 0 & 1 & 0 & 0 \\
\hline Changes count & 63 & 9 & 2 & 44 & 10 & 2 & 58 & 8 & 2 \\
$\mathbf{C}$ changes total & & 74 & & & 56 & & & 68 & \\
\hline & & & & & & & & & 0 \\
\end{tabular}

Table 11 shows average membership values of all generalized river networks where their patterns are preserved. From the table, the average membership value of river networks generalized by manual work is 0.59 , which is slightly greater than by catchment $(0.52)$ and by stroke and length (0.57). It indicates that, from the aspect of drainage patterns, river networks generalized by manual work are better than by catchment and stroke, which corresponds to the result from case studies. The average value given by the stroke and length method is close to the manual generalized river networks. Here the stroke is established based on the Horton-Strahler order after upstream routine, which has been considered as the one that "most closely approximates the generalisation decisions made by a human cartographer" [20].

Table 11. Average membership value of preserved patterns.

\begin{tabular}{cccc}
\hline Method & Stroke + Length & Catchment & Manual \\
\hline Average membership value & 0.57 & 0.52 & 0.59 \\
\hline
\end{tabular}


Some examples of river networks that change their patterns after generalization are illustrated in Figure 11. In the figure, (a-1) and (b-1) are original networks; $(a / b-2),(a / b-3)$ and $(a / b-4)$ are generalized river networks by stroke and length, catchment and manual work. Table 12 shows the assessment results of the generalized river networks. From the table, network (a-1) is dendritic, but generalized networks (a-2), (a-3) and (a-4) are changed to rectangular. For another example, network (b-2) and (b-4) alters the pattern from trellis to parallel, and network (b-3) still maintains the pattern.

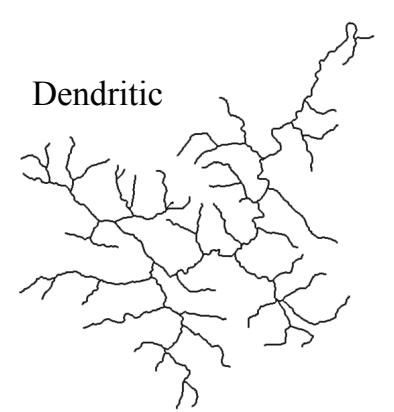

(a-1) Original

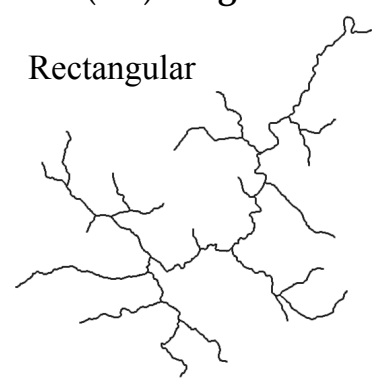

(a-3) Catchment

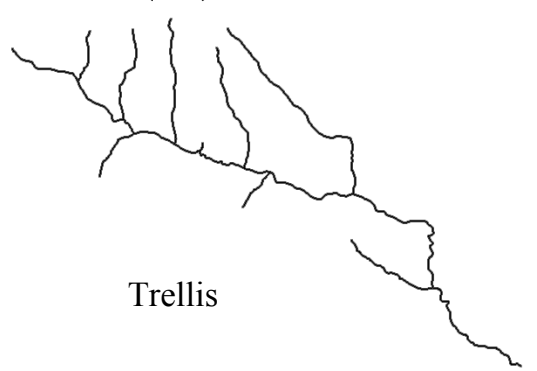

(b-1) Original

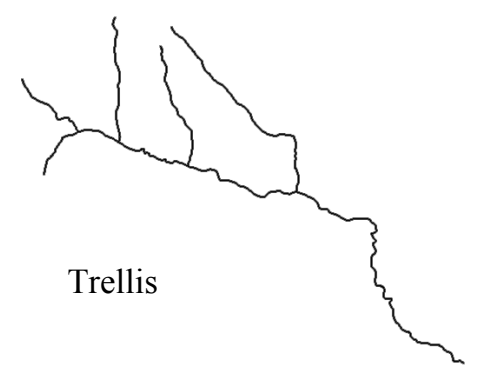

(b-3) Catchment

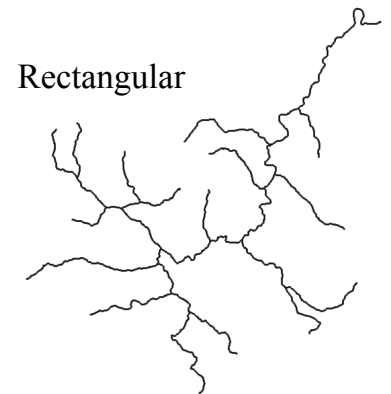

(a-2) Stroke + Length

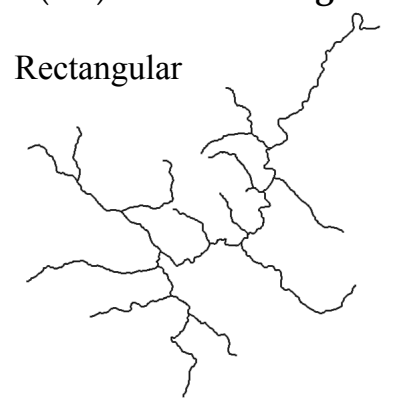

(a-4) Manual

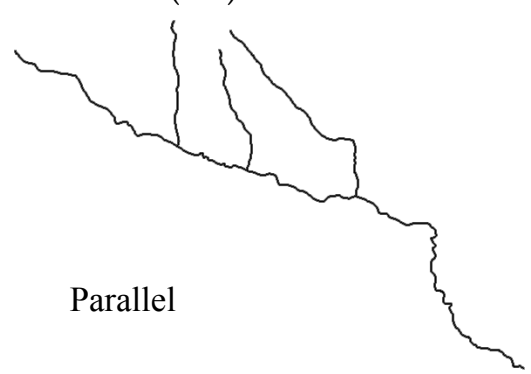

(b-2) Stroke + Length

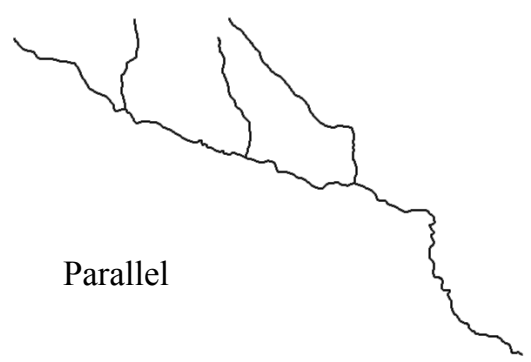

(b-4) Manual

Figure 11. Some generalized river networks with changed patterns. (a-1) Original; (a-2) Stroke + Length; (a-3) Catchment; (a-4) Manual; (b-1) Original; (b-2) Stroke + Length; (b-3) Catchment; (b-4) Manual.

From Table 12, the membership value of each river network is not so large. Therefore, we check the membership values of river networks that preserved or changed their patterns. For river networks 
that preserved their patterns after generalization, the average membership value of original river networks is 0.57 ; the average value is 0.30 only for river networks that changed patterns. It indicates that, in general, if the source river network has high membership value of a pattern (which has a significant pattern characteristic), it would be easier to preserve its pattern after generalization than a river network with low membership value.

Table 12. Assessment for river networks in Figure 11.

\begin{tabular}{ccccccccc}
\hline Network & \multicolumn{3}{c}{ Indicator } & \multicolumn{5}{c}{ Membership Value } \\
\hline & $\boldsymbol{\alpha}$ & $\boldsymbol{\beta}$ & $\boldsymbol{\gamma}$ & $\boldsymbol{\delta}$ & $\mathbf{D}$ & $\mathbf{P}$ & $\mathbf{T}$ & $\mathbf{R}$ \\
\cline { 2 - 9 }$(\mathrm{a}-1)$ & $83.52^{\circ}$ & $10 \%$ & 1.43 & 1.42 & $\mathbf{0 . 0 4 1}$ & 0 & 0 & 0.020 \\
$(\mathrm{a}-2)$ & $108.65^{\circ}$ & $29 \%$ & 0.84 & 1.42 & 0 & 0 & 0.053 & $\mathbf{0 . 1 6 9}$ \\
$(\mathrm{a}-3)$ & $100.80^{\circ}$ & $22 \%$ & 0.95 & 1.55 & 0 & 0 & 0.004 & $\mathbf{0 . 0 9 3}$ \\
$(\mathrm{a}-4)$ & $104.98^{\circ}$ & $23 \%$ & 0.97 & 1.46 & 0 & 0 & 0.001 & $\mathbf{0 . 1 0 2}$ \\
\hline (b-1) & $64.03^{\circ}$ & $5 \%$ & 0.13 & 3.17 & 0 & 0 & $\mathbf{0 . 0 3 4}$ & 0.006 \\
$(\mathrm{~b}-2)$ & $55.23^{\circ}$ & 0 & 0.23 & 4.32 & 0 & $\mathbf{0 . 0 5 1}$ & 0.002 & 0 \\
$(\mathrm{~b}-3)$ & $67.26^{\circ}$ & 0 & 0.22 & 2.78 & 0.025 & 0 & $\mathbf{0 . 0 7 5}$ & 0 \\
$(\mathrm{~b}-4)$ & $49.49^{\circ}$ & 0 & 0.22 & 4.32 & 0 & $\mathbf{0 . 0 9 3}$ & 0 & 0 \\
\hline
\end{tabular}

\subsection{Discussion}

From the experimental results, several conclusions can be given as follows.

1. In general, the evaluation method based on the membership degree of a fuzzy rule for a drainage pattern is useful. From a large scale to a small scale, to a generalized river network, the drainage pattern preserves better if the membership value is high. However, sometimes, the membership value will be not so robust at small scales, especially when there are not enough river segments left because proposed indicators, such as average junction angle $(\alpha)$, bent tributaries percentage $(\beta)$, and average length ratio $(\gamma)$, are statistical features.

2. By evaluating generalized river networks from the point of drainage patterns, the method based on stroke and length is better than based on watershed partitioning. In addition, networks generalized manually are always with high membership values and preserve a good drainage pattern. A good generalized result does not only depend on one or two factors; many factors such as tributary spacing and balance are involved in manual generalization process.

3. One limitation is that this research only focuses on the evaluation of the drainage pattern. Some other aspects simply cannot be assessed by the membership value. For example, for network (f) in Table 9 at the 1:500K scale, although the membership value is 0.896 , much greater than $(\mathrm{g})$, it is not an ideal result as the tributaries in the dashed circle are crowded together in Table 10.

4. Another limitation is that the evaluation method is more reliable and accurate in source river networks with order 3 or higher, but higher order is not always better because sub-networks can be classified in different patterns inside a large river network. A small river network with order 2 does not have enough river segments to provide robust indicators.

\section{Summary}

In this article, a quality assessment method based on fuzzy logic is provided to evaluate drainage patterns of a generalized river network. In these tests, generalization is completed by different tributary selection operations. The quality is evaluated by checking the membership value to a drainage pattern from a fuzzy rule. Four drainage patterns are evaluated in this study: dendritic, trellis, parallel and rectangular. The method was applied to evaluate different tributary selection methods, such as by stroke and length, by watershed portioning and by manual work. The experimental data is the Russian river from the RRIIS at 1:24K scale, and the NHD at 1:100K scale. 
From the experimental results, when the membership value is higher, the generalized river network is better. It is based on the assumption that the NHD data at the 1:100K scale is a better generalized dataset because it has been produced involving manual procedures which are the professional experiences of expert cartographers. During the generalization, the membership of generalized river networks can be higher than the original. That is because a generalized river network can have more characteristics of the pattern than the original network after generalization. This method is appropriate for evaluating a generalized river network from the perspective of drainage patterns. The advantage of this research is that evaluating a generalized river network based on fuzzy logic is easy to understand and implement. The limitations of the research are: (1) evaluation is focused on the drainage pattern only according to the membership value, other criteria may also be proposed; (2) the method is more suitable for a river network with order 3 and 4 , which is the order value of the main stream in the Horton-Strahler ordering scheme. This is because a small network does not have enough river segments and a large network can have many sub-networks with different patterns inside.

Existing methods of tributary selection do not consider the pattern in the first place, although at times they can preserve the pattern of a generalized river network. Considering the pattern is an important factor in river networks, and should be taken into account in river network generalization. In order to provide a better generalized river network, one future work should propose a tributary selection method with consideration of drainage patterns. As seen in this work, solely focusing on drainage patterns cannot generalize a river network as well as the manual method. The indicators influencing the drainage pattern can be considered in the generalization, however, other factors are also needed, such as tributaries balance and spacing. The future work needs to provide a solution to deal with multiple factors at the same time during the river network generalization.

Acknowledgments: This research was supported by the National Natural Science Foundation of China (41501496, 41271449), and Jiangsu Planned Projects for Postdoctoral Research Funds (1402061B).

Author Contributions: Ling Zhang performed the research, experiments and wrote the paper. Eric Guilbert co-wrote and edited the paper.

Conflicts of Interest: The authors declare no conflict of interest.

\section{References}

1. Chen, Y.; Wilson, J.P.; Zhu, Q.; Zhou, Q. Comparison of drainage-constrained methods for DEM generalization. Comput. Geosci. 2012, 48, 41-49. [CrossRef]

2. Li, Z.; Zhu, Q.; Gold, C. Digital Terrain Modeling: Principles and Methodology; CRC Press: Boca Raton, FL, USA, 2010.

3. Génevaux, J.-D.; Galin, É.; Guérin, E.; Peytavie, A.; Beneš, B. Terrain generation using procedural models based on hydrology. ACM Trans. Graph. 2013, 32, 1-10. [CrossRef]

4. Ai, T.; Liu, Y.; Chen, J. The hierarchical watershed partitioning and data simplification of river network. In Progress in Spatial Data Handling; Riedl, A., Kainz, W., Elmes, G.A., Eds.; Springer: Berlin/Heidelberg, Germany, 2006; pp. 617-632.

5. Buttenfield, B.P.; Stanislawski, L.V.; Brewer, C.A. Multiscale representations of water: Tailoring generalization sequences to specific physiographic regimes. In Proceedings of the GIScience 2010, Zurich, Switzerland, 15-17 September 2010; pp. 14-17.

6. Stanislawski, L.V. Feature pruning by upstream drainage area to support automated generalization of the United States National Hydrography Dataset. Comput. Environ. Urban Syst. 2009, 33, 325-333. [CrossRef]

7. Bard, S.; Ruas, A. Why and how evaluating generalised data? In Developments in Spatial Data Handling; Springer: Berlin/Heidelberg, Germany, 2005; pp. 327-342.

8. Twidale, C.R. River patterns and their meaning. Earth-Sci. Rev. 2004, 67, 159-218. [CrossRef]

9. Ritter, M.E. The Physical Environment: An Introduction to Physical Geography. Available online: http:/ / www.earthonlinemedia.com/ebooks/tpe_3e/title_page.html (accessed on 28 November 2016).

10. Charlton, R. Fundamentals of Fluvial Geomorphology; Routledge: London, UK, 2007. 
11. Fagan, S.D.; Nanson, G.C. The morphology and formation of floodplain-surface channels, Cooper Creek, Australia. Geomorphology 2004, 60, 107-126. [CrossRef]

12. Li, Z. Algorithmic Foundation of Multi-Scale Spatial Representation; CRC: Boca Raton, FL, USA, 2007.

13. Mackaness, W.; Edwards, G. The importance of modelling pattern and structure in automated map generalisation. In Proceedings of the Joint ISPRS/ICA Workshop on Multi-Scale Representations of Spatial Data, Ottawa, ON, Canada, 7-8 July 2002; pp. 7-8.

14. Zhang, L.; Guilbert, E. Automatic drainage pattern recognition in river networks. Int. J. Geogr. Inf. Sci. 2013, 27, 2319-2342. [CrossRef]

15. Topfer, F.; Pillewizer, W. The principles of selection. Cartogr. J. 1966, 3, 10-16. [CrossRef]

16. Wilmer, J.; Brewer, C. Application of the radical law in generalization of national hydrography data for multiscale mapping. In Proceedings of a Special Joint Symposium of ISPRS Technical Commission IV \& AutoCarto in conjunction with ASPRS/CaGIS 2010 Fall Specialty Conference, Orlando, FL, USA, 15-19 November 2010.

17. Mazur, R.E.; Castner, H.W. Horton's ordering scheme and the generalisation of river networks. Cartogr. J. 1990, 27, 104-112. [CrossRef]

18. Burghardt, D.; Duchene, C.; Mackaness, W. Abstracting Information in a Data Rich World: Methodologies and Applications of Map Generalization; Springer: Berlin, Germany, 2014.

19. Richardson, D.E. Automated Spatial and Thematic Generalization Using a Context Transformation Model: Integrating Steering Parameters, Classification and Aggregation Hierarchies, Reduction Factors, and Topological Structures for Multiple Abstractions; R\&B Publications: Kanata, ON, Canada, 1993.

20. Thomson, R.C.; Brooks, R. Efficient generalization and abstraction of network data using perceptual grouping. In Proceedings of the 5th International Conference on Geo-Computation, University of Greenwich, London, UK, 2000; pp. 23-25.

21. Touya, G. River network selection based on structure and pattern recognition. In Proceedings of ICC2007, Moscow, Russia, 4-10 August 2007; pp. 4-9.

22. Wolf, G.W. Weighted surface networks and their application to cartographic generalization. In Visualisierungstechniken und Algorithmen; Springer: Berlin, Germany, 1988; Volume 182, pp. 199-212.

23. Wu, H. Structured approach to implementing automatic cartographic generalization. In Prceedings of the 18th ICC, Stockholm, Sweden, 23-27 June 1997.

24. Zhai, R.J.; Wu, F.; Deng, H.; Tan, X. Automated elimination of river based on multi-objective optimization using genetic algorithm. J. China Univ. Min. Technol. 2006, 35, 403-408. (In Chinese)

25. Stanislawski, L.V.; Buttenfield, B.P. Hydrographic generalization tailored to dry mountainous regions. Cartogr. Geogr. Inf. Sci. 2011, 38, 117-125. [CrossRef]

26. Stanislawski, L.V. Development of a knowledge-based network pruning strategy for automated generalisation of the United States National Hydrography Dataset. In Proceedings of the 11th ICA Workshop on Generalization and Multiple Representation, Montpellier, France, 20-21 June 2008.

27. Savino, S.; Rumor, M.; Zanon, M. Pattern Recognition and Typification of Ditches. In Advances in Cartography and GIScience; Ruas, A., Ed.; Springer: Berlin/Heidelberg, Germany, 2011; Volume 1, pp. 425-437.

28. Muller, J.; Weibel, R.; Lagrange, J.; Salge, F. Generalization: State of the art and issues. In GIS and Generalization: Methodology and Practice; Taylor \& Francis: London, UK, 1995; pp. 3-17.

29. Weibel, R.; Dutton, G. Generalising spatial data and dealing with multiple representations. In Geographical Information Systems: Principles, Techniques, Management and Applications; Longley, P., Goodchild, M., Maguire, D., Rhind, D., Eds.; Springer: Berlin/Heidelberg, Germany, 1999; pp. 125-155.

30. Weibel, R. Three essential building blocks for automated generalization. In GIS and Generalization: Methodology and Practice; Taylor \& Francis: London, UK, 1995; pp. 56-69.

31. Joao, E. Causes and Consequences of Map Generalisation; Taylor \& Francis: London, UK, 1998.

32. Mackaness, W.; Ruas, A. Evaluation in the map generalisation process. In Generalisation of Geographic Information: Cartographic Modelling and Applications; Elsevier: Amsterdam, The Netherlands, 2007; pp. 89-111.

33. Bard, S. Quality assessment of cartographic generalisation. Trans. GIS 2004, 8, 63-81. [CrossRef]

34. Stanislawski, L.V.; Buttenfield, B.P.; Doumbouya, A. A rapid approach for automated comparison of independently derived stream networks. Cartogr. Geogr. Inf. Sci. 2015, 42, 435-448. [CrossRef]

35. Skopeliti, A.; Tsoulos, L. A methodology for the assessment of generalization quality. In Proceedings of the Fourth ACI Workshop on Progress in Automated Map Generalization, Beijing, China, 2-4 August 2001. 
36. Zhang, X. Automated Evaluation Of Generalized Topographic Maps. Ph.D. Thesis, The University of Twente, Enschede, The Netherlands, 4 October 2012.

37. Schumm, S.A. The Fluvial System; Wiley: New York, NY, USA, 1977.

38. Zadeh, L.A. Fuzzy sets. Inf. Control 1965, 8, 338-353. [CrossRef]

39. Thomson, R.C. The stroke concept in geographic network generalization and analysis. In Progress in Spatial Data Handling; Springer: Berlin/Heidelberg, Germany, 2006; pp. 681-697.

40. Braden, B. The surveyor's area formula. Coll. Math. J. 1986, 17, 326-337. [CrossRef]

41. USEPA; USDOI. Standards for National Hydrography Dataset; United States Environmental Protection Agency and United States Department of the Interior, United States Geological Survey: Reston, VA, USA, 1999.

(C) 2016 by the authors; licensee MDPI, Basel, Switzerland. This article is an open access article distributed under the terms and conditions of the Creative Commons Attribution (CC-BY) license (http://creativecommons.org/licenses/by/4.0/). 